have been published which are not mentioned in the bibliography : first, the book referred to at the beginning of this notice, the special contribution of which lies in the description of macro surface measurements and in the treatment of molecular flow phenomena during gas flow; secondly, a contribution on porous masses to Volume 2 of "Chemical Engineering Practice" (Butterworths; 1956), which in slightly more than half the pages covers the same field as the book under review but treats the subjects from a chemical engineering angle. PaUL Eismantam

\section{BIOPHYSICAL TECHNIQUES}

\section{Physical Techniques in Biological Research}

Edited by Gerald Oster and Arthur W. Pollister. Vol. 1 : Optical Techniques. Pp. xiii +564 . 96s. $6 d$. (1955). Vol. 2: Physical Chemical Techniques. Pp. $\mathrm{xv}+502.91 s .6 d .(1956)$. Vol. 3 : Cells and Tissues. Pp. $\mathrm{xv}+728$. 118s. (1956).

(New York: Academic Press, Inc.; London : Academic Books, Ltd.)

HESE volumes contain a large number of articles on the various physical techniques which are applied to biological materials. Such a collection is undoubtedly of value for reference purposes and can be recommended for the reference shelf of nearly all biological laboratories. No doubt much of the information provided could be found elsewhere, but it is often a convenience to have it in one set of volumes which can be consulted rapidly. At the same time there may be some doubt as to the class of reader at which it is aimed. The biologist on the whole will need the help of the physical or physicochemical specialists in operating many of these techniques; while the specialist will want to look at the original papers.

It is inevitable that a compilation of this sort cannot include the latest developments; and these are often the most interesting. One gots the impression that the editors have made a great effort to include all possible physical approaches. This has resulted in space being given to techniques which are of minor importance, which could with advantage have been omitted.

Turning now to the individual articles, we find in Vol. 1 ("Optical Techniques") articles covering spectrophotometry (visible, ultra-violet and infra-red) which are well done. The chapters on the light microscope and interference microscope discuss the theory of these instruments at considerable length. No doubt biologists would profit from a better understanding of these prineiples, but it may be doubted whether in fact many would make the study of the physical principles which is required. What would perhaps be more useful is a critical evaluation of the different types of instruments. The section on electron microscopy, although it is suitable for anyone who wanted to become acquainted with the principles and requirements of the method, is inadequate for an electron microscopist.

Vol. 2 ("Physical Chemical Techniques") covers an enormous range of methods, from the use of isotopic tracers and ionizing radiations to surface films and electrophoresis. The article by the late Kurt Stern on electrophoresis is a particularly good survey of practical aspects, up to the time of writing. On the other hand, the information given in the article of Spiegler and Wyllie on electrical potential differences really belongs to a text-book of physical chemistry, and it would have been better to make it more practical and more directed at the biological users;

On the whole, much that is given in these volumes will be found in a good text-book of physical chemistry, and I cannot help thinking that the editors have fallen between two stools. They should oither have: produced a text-book of physics and physical chemis. try in its application to biology; or havo limited. themselves much more closely to what their titlo implies, that is, techniques. The chapter on magnetic methods by Scott Blois illustrates the difficulties of this kind of compilation. A reader might well look for information on the developing subject of paramagnetic resonance applied to biological materials; but it is dismissed in a very few pages, and he would be forced to look elsewhere to find out what the method involves in practice and also to find the results obtained up to the present.

In Vol. 3 we come to the applications to real biological systems-cells and tissues. This is in the part of the book which fits the title best and which biologists will find most useful. However, the general considerations given above still apply to some extent.

J. A. V. Butler

\section{COMPUTERS}

An Introduction to Automatic Digital Computers By R. K. Livesley. (Cambridge Engineering Series.) Pp. viii $+53+4$ plates. (Cambridge : At the University Press, 1957.) 8s. 6d. net.

$\mathbf{N}$ this book the author attempts to explain to engineers and postgraduate students the way in which a computer works and its application to actual problems. The book is short and the approach unusual in that the author commences with the programming of simple problems and from a discussion of this aspect of computing leads to an account of the way in which a computer works.

The second chapter is devoted to different kinds of input and output mechanisms and storage organs which are in general use at the present time; the third chapter returns to the programming side with a consideration of the methods of constructing programmes for the solution of specific problems; and the work concludes with an examination of the way in which computers are likely to affect engineers in their approach to different problems.

In such a short book it is, of course, impossible for the author to deal to any great extent with real problems, but those examples given are well chosen and form a good basis for a more detailed study of the subject from other books, and the selected bibliography should help in this way.

The author expresses no extreme views. Some of the statements regarding actual problems might perhaps have been improved by more discussion, notable examples being the remarks on automatic programming (p. 38) and on linear programming (p. 46), but the only real fault in the book lies in the omission of an index.

The author's style, the general production and the material are good, and these together with the low price should make it useful to all students of this subject. 